\title{
RECENT PROGRESS IN RESIDUAL STRESS MEASUREMENT TECHNIQUES ${ }^{\star \star \star}$
}

\author{
Xianfu Huang ${ }^{1 \star} \quad$ Zhanwei Liu ${ }^{1 \star \star} \quad$ Huimin Xie ${ }^{2 \star \star}$ \\ $\left({ }^{1}\right.$ School of Aerospace Engineering, Beijing Institute of Technology, Beijing 100081, China) \\ $\left({ }^{2}\right.$ AML, Department of Engineering Mechanics, Tsinghua University, Beijing 100084, China)
}

Received 13 September 2013

\begin{abstract}
Residual stress measurement is of critical significance to in-service security and the reliability of engineering components, and has been an active area of scientific interest. This paper offers a review of several prominent mechanical release methods for residual stress measurement and recent developments, focusing on the hole-drilling method combined with advanced optical sensing. Some promising trends for mechanical release methods are also analyzed.
\end{abstract}

KEY WORDS residual stress, mechanical release method, hole drilling, moiré interferometry, holography; ESPI, digital image correlation

\section{INTRODUCTION}

Residual stress ${ }^{[1]}$ is the stress within a material that remains stationary and at equilibrium with its surroundings. It is always generated during fabrication, concatenating or heat treatment ${ }^{[2]}$ and is caused by non-uniform elastic or elastoplastic deformation due to the effect of applied stresses, temperature variation or chemical actions.

Residual stress can be very detrimental to the performance of a material and the life of a component. As early as 1860 , Wohler ${ }^{[3]}$ proposed the validation of structures based on fatigue strength and indicated that residual stress contributed to the fracture of train axles. During operation, the working stress superimposed on internal residual stress reduces the margin of safety within the material. On one hand, it adds to the level of deformation a component undergoes as well as a redistribution of the residual stress leading to a reduction of stiffness and dimensional stability ${ }^{[4]}$. On the other hand, for materials in harsh environments, residual stress couples with extreme temperature, overload, heat flux and strong erosion to contribute to fatigue strength $\operatorname{loss}^{[5,6]}$, Stress Corrosion Cracking (SSCC) behavior ${ }^{[7]}$ and creep cracking resistance ${ }^{[8]}$. A large number of engineering accidents and disasters have been linked to residual stress, hence residual stress measurement has significant practical implications in the service, security and reliability of components. Such measurements can also feedback data to heat treatment, surface strengthening, stress relief or scrap diagnosis processes to improve material performance.

\footnotetext{
* Present address: State Key Laboratory of Nonlinear Mechanics, Institute of Mechanics, Chinese Academy of Sciences, Beijing 100190, China.

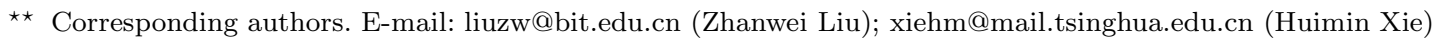

$\star \star \star$ The authors are grateful to the financial support from the National Basic Research Program of China (Project '973') (Nos. 2010CB631005 and 2011CB606105), the National Natural Science Foundation of China (Nos. 91216301, 11172151, 11232008, 11072033 and 11372037), Tsinghua University Initiative Scientific Research Program, Program for New Century Excellent Talents in University (grant No. NCET-12-0036), Natural Science Foundation of Beijing, China (grant No. 3122027).
} 
Residual stress measurements date back to the 1930s, with dozens of methods subsequently being developed ${ }^{[9]}$. They can be divided into two categories depending on whether damage will be caused to the specimen or not: Mechanical release methods ${ }^{[10]}$ such as the hole-drilling, sectioning, ring core, crack compliance and layer removal; and physical determination ${ }^{[1-15]}$ such as X-ray diffraction, magnetics, ultrasonics and Raman methods.

Mechanical release methods locally separate or split the component to release the residual stress, resulting in damage. Measurement is achieved by using strain gauges, moiré interferometry, holography, laser speckle interferometry and/or DIC ${ }^{[16-18]}$. Such methods are very well developed and the theory is well understood.

Non-destructive methods include several well established techniques that are all relatively expensive. X-ray diffraction can only be used as a surface measurement technique for certain crystalline materials and is sensitive to surface preparation. Magnetic testing methods can only be used on magnetic materials and are based on the changing relationship between stress and the magnetization curve in the process of ferromagnetic saturation. And ultrasonic testing ${ }^{[19]}$ is simple in principle, and is suitable for depthvarying residual stress measurements although there are still some difficulties to overcome ${ }^{[20,21]}$ such as distinguishing sound velocity changes caused by materials defects or stress.

Mechanical release methods, although seemingly less attractive than non-destructive methods because of the damage they cause to specimens, are often the preferred choice because of their versatility and reliability. Among them, the small diameter and shallow blind-hole method, which causes less damage and is fairly accurate, makes it one of the most popular standard methods in the field. This paper will review and summarize recent developments and application of residual stress measurement techniques using mechanical release methods combined with advanced optical sensing, with emphasis on the hole-drilling method combined with optical measurement. It concludes with an analysis and indication of some promising trends in this area.

Table 1 summarizes the major methods for residual stress measurement.

Table 1. A comparison of the major methods used for residual stress measurement

\begin{tabular}{|c|c|c|c|c|}
\hline Method & Penetration & Spatial resolution & Accuracy & Comments \\
\hline $\begin{array}{l}\text { Hole } \\
\text { drill }\end{array}$ & $\sim 1.2 \times$ hole diameter & $50 \mu \mathrm{m}$ length & $\pm 50 \mathrm{MPa}$ & $\begin{array}{l}\text { Three dimensional stress } \\
\text { by in-plane point measurement; } \\
\text { semi-destructive; economical }\end{array}$ \\
\hline Sectioning & Specimen thickness/length & $>1 \mathrm{~mm}^{3}$ & $\begin{array}{l} \pm 1.38 \mathrm{MPa} \text { (for } \\
\text { three measurements) }\end{array}$ & $\begin{array}{l}\text { Accurate and economical when only } \\
\text { the longitudinal stress are important; } \\
\text { creates irreversible destruction }\end{array}$ \\
\hline $\begin{array}{c}\text { Layer } \\
\text { removal }\end{array}$ & $0.1 \sim 0.5$ of thickness & 0.05 of thickness & $\begin{array}{l}\text { Limited by minimum } \\
\text { measurable curvature }\end{array}$ & $\begin{array}{l}\text { Three dimensional stress by layer to } \\
\text { layer removal; can be time consuming }\end{array}$ \\
\hline Magnetic & $10 \mathrm{~mm}$ & $1 \mathrm{~mm}$ & $10 \%$ & $\begin{array}{l}\text { Nondestructive for magnetic } \\
\text { materials only; economical device; } \\
\text { in-plane stress measuement }\end{array}$ \\
\hline $\begin{array}{c}\text { X-ray } \\
\text { diffraction }\end{array}$ & $\begin{array}{l}<50 \mu \mathrm{m}(\mathrm{Al}),<5 \mu \mathrm{m}(\mathrm{Ti}) \\
<1 \mathrm{~mm}(\text { with layer removal) }\end{array}$ & $\begin{array}{l}1 \mathrm{~mm} \text { diameter } \\
20 \mu \mathrm{m} \text { depth }\end{array}$ & $\pm 20 \mathrm{MPa}$ & $\begin{array}{l}\text { Nondestructive only as a surface } \\
\text { technique; in-plane stress; sensitive to } \\
\text { surface roughness; costly equipment }\end{array}$ \\
\hline Ultrasonic & $>10 \mathrm{~cm}$ & $5 \mathrm{~mm}$ & $\pm 50 \times 10^{-6}$ strain & $\begin{array}{l}\text { Nondestructive; sensitive to micro- } \\
\text { structures and defects; limited by } \\
\text { reliability of stress free references }\end{array}$ \\
\hline Raman & $<1 \mu \mathrm{m}$ & $\stackrel{\sim}{\sim} \mu \mathrm{m}$ & $\begin{array}{c}50 \mathrm{MPa} \\
\left(\equiv \Delta \lambda \approx 0.1 \mathrm{~cm}^{-1}\right)\end{array}$ & $\begin{array}{l}\text { Sensitive to surface roughness; } \\
\text { costly equipment }\end{array}$ \\
\hline
\end{tabular}

\subsection{Strain Gauge Rosette Hole-Drilling}

\section{HOLE-DRILLING METHOD}

The hole-drilling method, pioneered by Mathar ${ }^{[22]}$ in 1934, is one of the most popular techniques used to measure residual stress. The theory of the hole-drilling method was established by Soete ${ }^{[23]}$ and Rendler et al. ${ }^{[24]}$, and was further developed in application range. The rationale of the measurement is to install a highly sensitive strain rosette on the sample surface (under stress equilibrium state) and then mechanically drill a hole in the rosette center. The material removal will cause a stress relaxation in the locality around the circular hole measured by the strain rosette method, i.e. it will destroy the former equilibrium state and attain a new stress distribution resulting in the surrounding material deformation, namely, strain relief. 
The average principal stress and orientation $\left(\sigma_{\max }, \sigma_{\min }, \beta\right)$ can be calculated using elastic theory ${ }^{[16,17]}$, the corresponding formulas can be expressed as follows:

$$
\begin{aligned}
& \sigma_{\text {max }, \text { min }}=\frac{\varepsilon_{1}+\varepsilon_{2}}{4 A} \pm \frac{1}{4 B} \sqrt{\left(\varepsilon_{1}-\varepsilon_{2}\right)^{2}+\left[2 \varepsilon_{3}-\left(\varepsilon_{1}+\varepsilon_{2}\right)\right]^{2}} \\
& \tan (2 \beta)=\frac{2 \varepsilon_{3}-\left(\varepsilon_{1}+\varepsilon_{2}\right)}{\varepsilon_{2}-\varepsilon_{1}}
\end{aligned}
$$

where $\varepsilon_{1}, \varepsilon_{2}$ and $\varepsilon_{3}$ are strains obtained using the strain rosette (consisting of three strain gauges); $A$ and $B$ are release coefficients; and $\beta$ is the angle between the orientation of the principal stress $\sigma_{\max }$ and the axis of strain gauge 1, as illustrated in Fig.1.

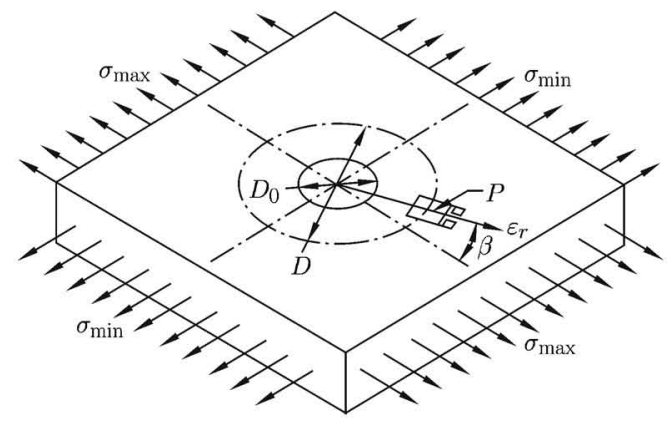

(a)

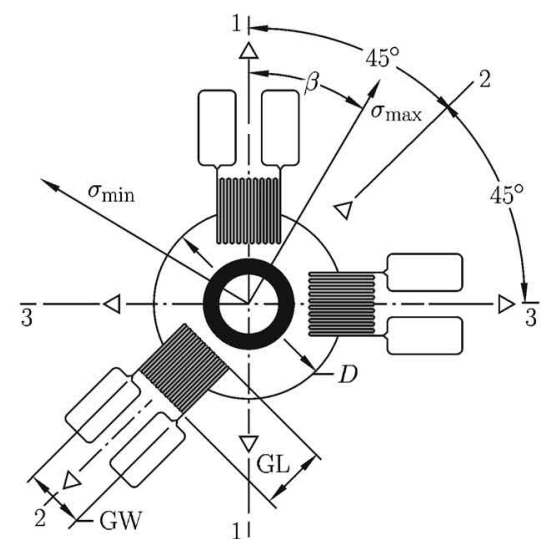

(b)

Fig. 1. A schematic diagram illustrating (a) symbol definition and (b) a typical strain gage rosette for the hole-drilling $\operatorname{method}^{[16]}$.

The hole-drilling method is relatively simple, causing very little damage and being effective, extremely precise, practical to implement, and capable of evaluating residual stress in a wide range of engineering applications. In addition, the method is suitable for measuring depth-varying residual stress by using incremental hole-drilling steps. The American Society for Testing Materials (ASTM) has established two comprehensive standards ${ }^{[16,17]}$ for this method.

The main limitations with conventional strain gauge measurements are: the restricted range of hole geometry, the specific gauge rosette design, the need for accurate alignment during the hole-drilling process, and the limited strain data averaged within the length range of the strain gauge used. Recently, with the development of photoelectric technology, advanced optical sensors have been combined with such mechanical release methods to measure residual stress. Optical methods are able to make much more complex measurements and have the advantage of obtaining full-field deformation data and non-contact, improved accuracy.

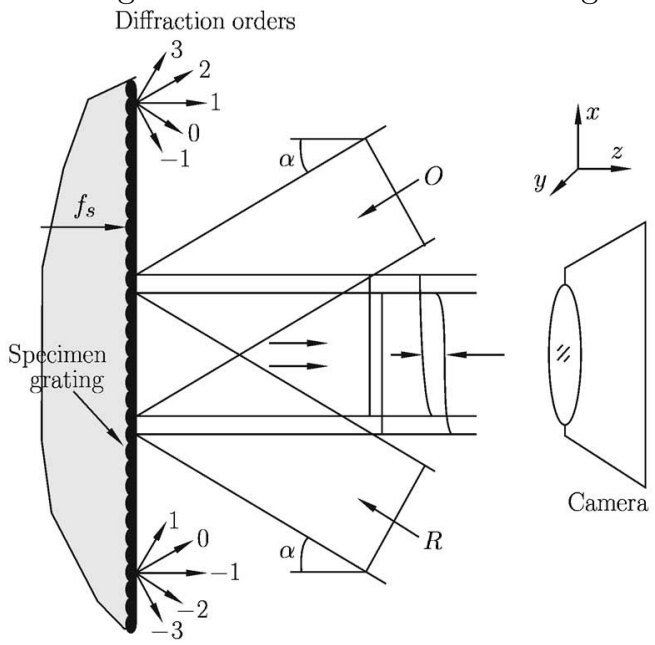

Fig. 2 A schematic diagram illustrating moiré interferometry measurement.

\subsection{Moiré Interferometry Hole-Drilling}

Moiré interferometry ${ }^{[25]}$ (Fig.2) is a modern photomechanical method with a number of advantages such as high sensitivity, good fringe quality and real-time measurement. Since its development in the 1980s, successful applications have been achieved in a variety of fields such as structural strength, vibration, fatigue and creep measurement. 
This method was first proposed by McDonach ${ }^{[26]}$ and further developed by Nicoletto ${ }^{[27]}$ who drilled a series of holes at small intervals and analyzed the moiré fringes caused by stress relaxation to obtain a graded distribution of in-plane residual stress.

Dai et al. ${ }^{[28-32]}$ carried out many studies in this area. They used moiré interferometry instead of strain gauge rosettes to measure the displacement caused by stress relaxation after hole drilling and then established the relationship between displacement and residual stress using FEM. A portable moiré interferometry hole-drilling system which can be used for field measurement has also been developed and successfully applied to the measurement of residual stress of welded joints and other components.

In 2003, Ya and Dai et al. ${ }^{[33]}$ introduced the full theory, experimental method and application for the measurement of non-uniform (both in-depth and in-plane) residual stress using the moiré interferometry hole-drilling method. In 2004, Shankar and Xie et al. ${ }^{[34]}$ conducted a study on the residual stress within polymer composites, and Xie et al. ${ }^{[35]}$ studied the residual deformation in lap-welded steel plates, as shown in Fig.3.
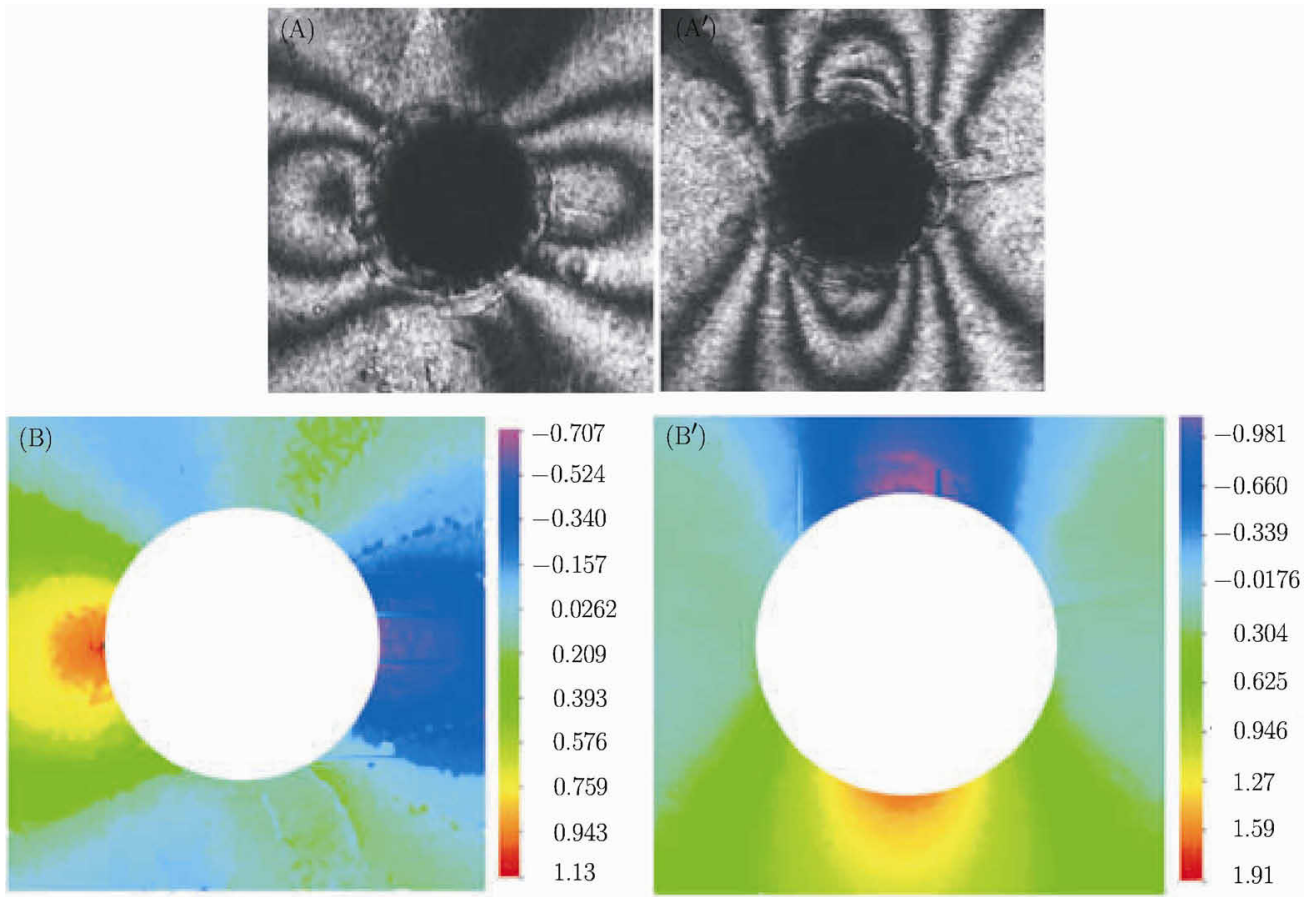

Fig. 3. $U_{x}$ and $U_{y}$ moiré patterns created by residual stress relaxation after hole-drilling showing the $U_{x}$ field and $U_{y}$ field (field size: $4 \mathrm{~mm} ; x$ and $y$ directions are perpendicular to and along the weld direction separately) showing: (A) $U_{x}$ field moiré pattern; ( $\left.\mathrm{A}^{\prime}\right) U_{y}$ field moiré pattern; (B) $U_{x}$ field map of pattern (A); (B') $U_{y}$ field map of pattern $\left(\mathrm{A}^{\prime}\right)$. (Reprinted with permission. Ref.[35] Copyright 2011, John Wiley \& Sons)

Chang et al. ${ }^{[36]}$ applied a phase-shift moiré interferometry method combined with the blind-holedrilling for composite materials. Chen et al. ${ }^{[37,38]}$ developed a grating rosette with $3 \mathrm{D}$ sensitivity based on the moiré interferometry hole-drilling method which was successfully used for various materials. $\mathrm{Zou}^{[32]}$ and Liu et al. ${ }^{[39-42]}$ provided a novel way to measure the welded residual stress of a curved surface using the moiré interferometry hole-drilling method combined with an advanced grating transfer method and geometric phase analysis (GPA).

Compared with the conventional hole-drilling method combined with strain gauge rosette measurement, the moiré interferometry hole-drilling method has two main advantages: The first is that the measuring point can be selected after the hole-drilling process due to full-field measurement of the fringe pattern; for a strain gauge rosette measurement, the measurement sites are fixed and invariable which may lead to an incorrect strain value. The second is that the measured values from strain gauge rosette are averaged making the computation of residual stress an average; while using moiré interferometry 
the displacement values can be obtained point-by-point meaning that a non-uniform residual stress field can be derived using specific algorithms. The application of moiré interferometry to the hole-drilling method not only expands the scope of the method, but also improves measurement precision.

\subsection{Digital Image Correlation Hole-Drilling}

Digital Image Correlation (DIC) ${ }^{[43-45]}$ is a versatile optical technique which has been rapidly developed over the last few years and widely applied to the measurement of surface displacement fields in two or three dimensions. It is based on the analysis of two digital textured images captured from the specimen surface before and after deformation using a high-resolution digital camera typically set perpendicular to the surface with two cameras being used for 3D measurements. The local textured detail within the two images are then statistically correlated and their relative displacements can be determined. Figure 4 illustrates the set-up used for 2D DIC.

DIC has been successfully applied to many residual stress measurements. Nelson et al. ${ }^{[46,47]}$ were the first to describe the application of DIC with hole drilling and reported results for blind-hole measurements on a shrink fit ring sample

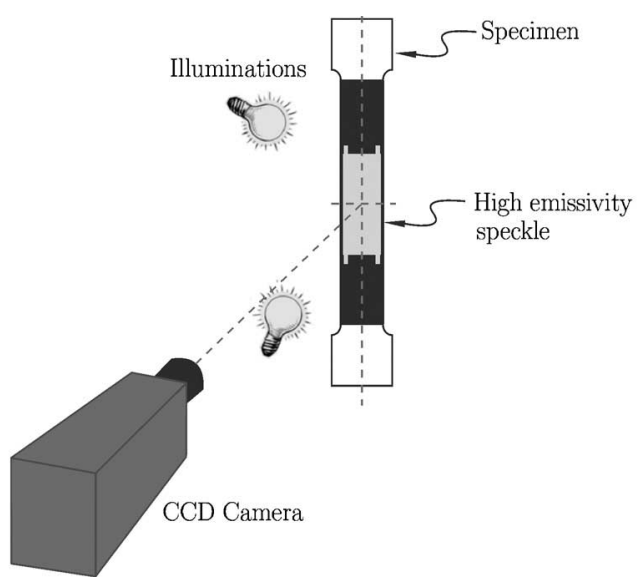

Fig. 4 Schematic of the setup used for $2 \mathrm{D}$ digital image correlation.

using a 3D DIC system with two Megapixel cameras. In 2008, Lord et al. ${ }^{[4]}$ integrated DIC measurement with incremental hole-drilling and applied integral method analysis to measure the variation of residual stress with depth (Fig.5); validation data were in good agreement with those determined by hole drilling with conventional strain gauge data and FE models verifying effectiveness and reliability, as shown in Fig.6.
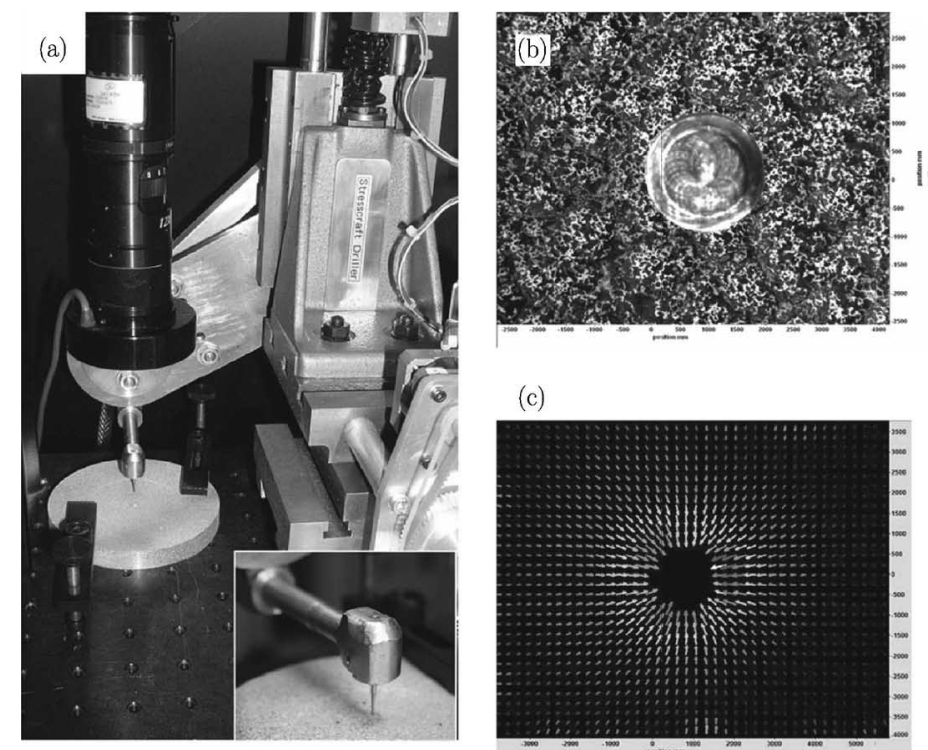

(c)

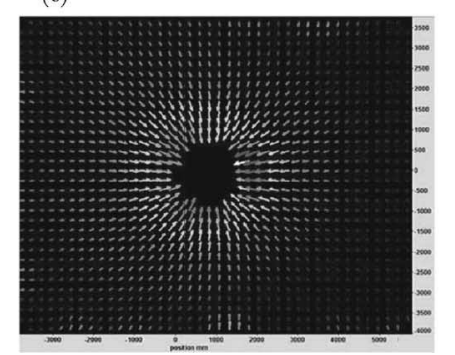

Fig. 5. (a) DIC hole-drilling setup; (b) speckle pattern after drilling; (c) DIC vector plot around the hole after stress release. (Reprinted with permission. Ref.[47] Copyright 2008, Trans Tech Publications Inc.)

In 2009, Gao \& Shang ${ }^{[48]}$ described a new approach for directly determining the residual stress with DIC hole drilling using the deformation pattern, governed by the residual stress, to transform the image captured after the deformation of the object. If the values of trial residual stress components are properly chosen, the image after the transformation will have a maximum similarity to the original image. This turns the residual stress measurement into a pure numerical computational process, which 


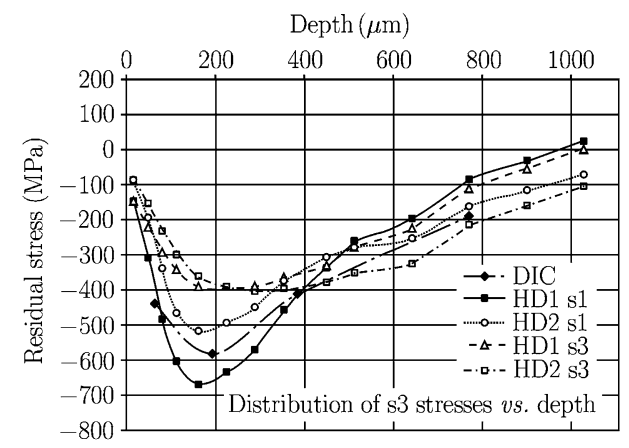

Fig. 6. Comparison of shot-peening residual stresses determined by DIC-hole drilling method with strain gage measurements. Principal stresses are denoted by s1 and s3. (Reprinted with permission. Ref.[47] Copyright 2008, Trans Tech Publications Inc.)

leads to the direct output of residual stress. Xie et al. ${ }^{[49]}$ and Yao et al. ${ }^{[50]}$ carried out many studies on this, as well as on the DIC hole-drilling method.

Even very small or micro- specimens (e.g. micromechanical devices) have been investigated using this method. In 2007, Sabaté et al. ${ }^{[51]}$ described the use of the hole-drilling method with DIC to determine residual stress in thin films using a $4.5 \mu$ m diameter hole created by a Focused Ion Beam (FIB) milling, with DIC being implemented using scanning electron microscopy. The use of micro-holes with DIC has followed the initial use of micro-slots for stress release.

The benefits of using DIC over other non-contact methods include the potential for rapid measurement with simple surface preparation, applicability to rough or curved surfaces, the ability to correct rigid body motion, and the limited amount of specialized equipment required. The DIC method is less sensitive to environmental disturbances than moiré, and so is more suitable and convenient for on-site use.

\subsection{Laser Speckle Interferometry Hole-Drilling}

Speckle interferometry is a class of laser interference methods which also include Electronic Speckle Pattern Interferometry (ESPI) and Shearography ${ }^{[52,53]}$. When a stress is applied to a component, the surface of the material deforms and a change in the interference fringe pattern occurs. Through analysis of the fringe pattern, the stress distribution of the component can be derived and the strain relief caused by hole-drilling can be measured.

The ESPI hole-drilling method was first proposed by Zhang et al. ${ }^{[54,55]}$ in the late 1990s. They established an optic fiber ESPI hole-drilling system and measured the residual stress of some standard samples. Schmitt and Hunt ${ }^{[56]}$ analyzed the equations in detail for stress calculation from the ESPI patterns. Steinzig and Ponslet ${ }^{[57-60]}$ put forward a systematic single-beam ESPI hole-drilling method and error analysis, and provided some practical demonstration experiments with the technique subsequently becoming commercialized. Xiao et al. ${ }^{[61]}$ measured out-of-plane displacements caused by peening residual stress relaxation using the commercialized ESPI system. Díaz et al. ${ }^{[62]}$ measured the residual stress of an aluminum sheet bearing uniaxial uniform tension load with the ESPI hole-drilling method, as the optical set-ups shown in Fig.7. And Hung et al. ${ }^{[63]}$ measured the residual stress of a component using the Shearography hole-drilling method, as shown in Fig.8.

Compared to the moiré interferometry hole-drilling method, the ESPI/Shearography hole-drilling method can be applied to measuring a rough/uneven surface without transferring a coating or grating onto it. Compared with the strain gauge measurement, the ESPI/Shearography hole-drilling method is more efficient and gives more detail on deformation information around the drilled hole. Moreover, the method can be applied to a wider range of materials and surfaces. However, the ESPI hole-drilling method can only measure the surface residual stress and is sensitive to ambient vibration, which limits applications to controlled laboratory environments. As with the Shearography hole-drilling method, quantitative results from the shearing interferogram are hard to calculate. 


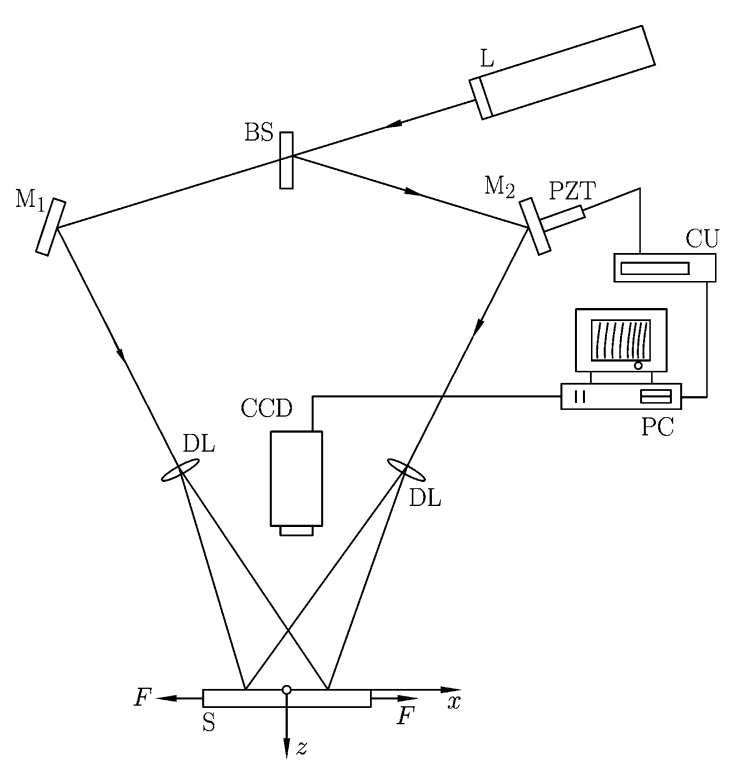

Fig. 7. ESPI system for measuring in-plane-relieved displacement component $u(x, y)$ : (L) He-Ne laser; (BS) beamsplitter; (M1 and M2) mirrors; (DL) divergent lens; (CCD) video camera; (S) test specimen; (PC) digital image processing system; (PZT) piezoelectric transducer for phase shifting measurement; (CU) controller unit.

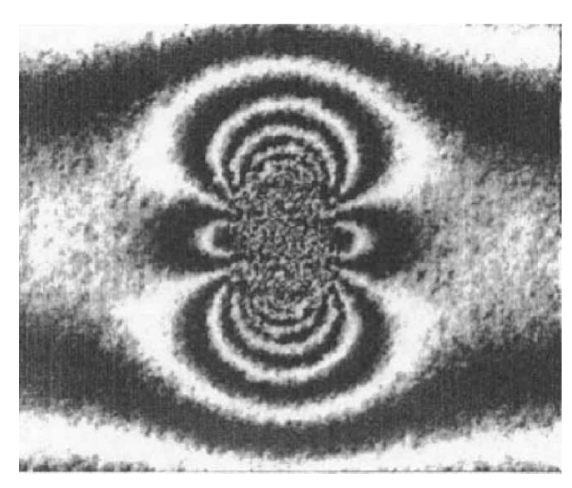

Fig. 8. Shearography fringe pattern around the hole after stress release. (Reprinted with permission. Ref.[63] Copyright 1997, Elsevier)

\subsection{Holography Hole-Drilling}

A widely used non-contact, high precision optical method, holography is successfully applied to measuring deformations due to vibration, high temperature, and so on. The principle and application is detailedly described in literature [64-66]. Holography appears to have been the first optical method applied with hole-drilling not requiring the application of a coating or grating. Studies on this date back to the mid-1980s when Steffens ${ }^{[67]}$ combined holography and hole-drilling despite his failure to make clear the relationship between residual stress and fringe orders. Later, Antonov ${ }^{[68]}$, Lobanov ${ }^{[69]}$ and Rassokha et al. ${ }^{[70]}$ focused on this aspect and intensively studied welded residual stress measurements. They used holography to measure the out-of-plane displacement around a drilled hole, however, in most cases, residual stresses are in-plane stress with out-of-plane displacements being very small. Makino and Nelson ${ }^{[71,72]}$ used the holography hole-drilling method to calculate the relative fringe orders to measure the in-plane displacement. Steinzig et al. ${ }^{[73]}$ developed a commercial system called PRISM that combined hole drilling with holography for the full-field noncontact strain measurement. The optical set-ups used for holographic interferometry and a typical holographic pattern by hole-drilling is shown in Fig.9.

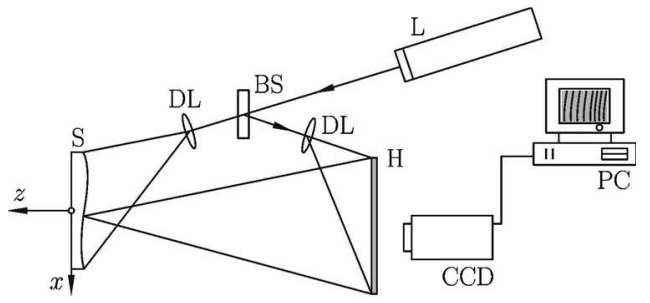

(a)

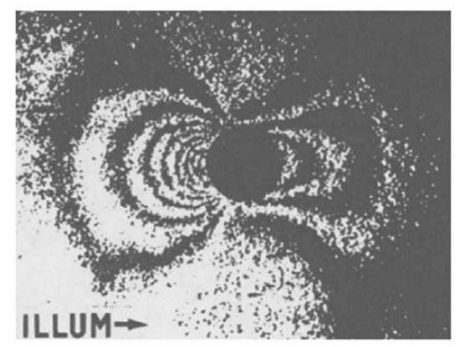

(b)

Fig. 9 (a) Optical set-ups used for holographic interferometry: (L) He-Ne laser; (BS) beam-splitter; (DL) divergent lens; (CCD) video camera; (S) test specimen; (PC) digital image processing system; (b) A typical holographic pattern by hole-drilling. (Figure (b) adapted with kind permission. Ref.[71] Copyright 1986, Springer)

Early studies into the holography hole-drilling method were largely dependent on recording the fringe pattern using silver holographic plates and counting the fringe pattern manually. With the rapid development in digital technology, digital holography had the advantage of automatic and quantitative analysis of interference patterns which not only reduced human error but also shortened the processing time. 
A major advantage of the holography hole-drilling method is that it is a non-contact technique that can obtain the in-plane displacement field using a uniaxial hologram without the requirement for surface preparation. A drawback is that rigid body motion can easily be introduced during the measuring process and the speckle noise in the holographic pattern disturbs the determination of fractional fringe orders.

\section{SECTIONING METHOD}

The sectioning method has been used for several decades to measure residual stresses in structural materials and is based on the principle that internal stresses are relieved by cutting out parts of the specimen. It is best applied when only longitudinal stresses alone (uniaxially distributed) are important, simplifying analysis by assuming that the transverse stresses are negligible. The residual stress distribution through the thickness of a plate can be determined from changes of strain readings after 'slicing' the sawed pieces. Since 1970, FEM had been applied to the sectioning method, which greatly improved the measuring accuracy. Many practical issues such as 3D residual stress of welded joint could then be done. Tebedge et al. ${ }^{[7]}$ made a sequence of cuts to evaluate the residual stresses in an I-beam section.

The sectioning method combined with optical methods to evaluate residual stress has also been carried out by researchers. Liu et al. ${ }^{[75]}$ developed a moiré interferometry-sectioning method and measured the residual stress of a shot-peening specimen along its thickness, as illustrated schematically in Fig.10.

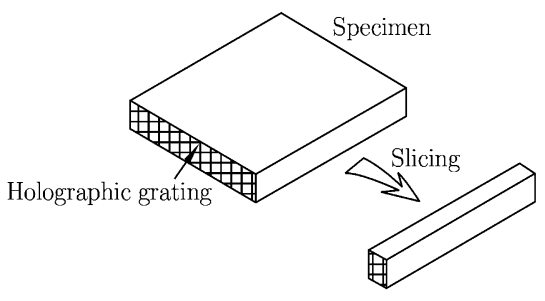

(a)

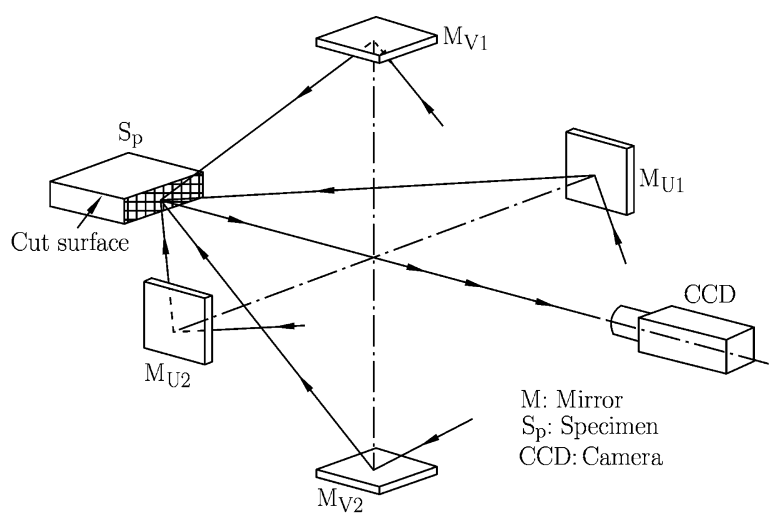

(b)

Fig. 10. Schematic diagrams of (a) the sectioning method and (b) the optical setup for strain relief measurement using moiré interferometry after stress release.

Zhu et al. ${ }^{[76]}$ measured the residual stress of a thermal barrier coating along the interface using the moiré interferometry sectioning method, the results of which are illustrated in Fig.11.

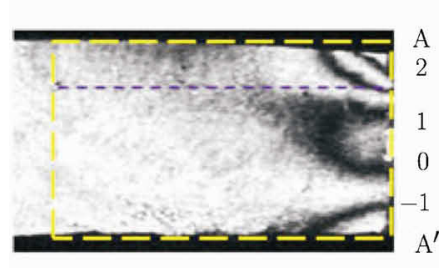

(a)

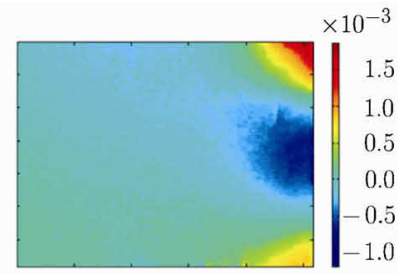

(b)

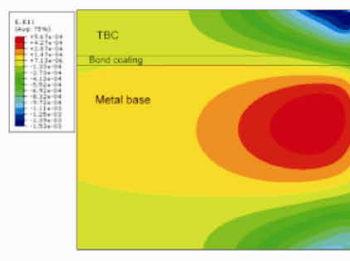

(c)

Fig. 11. Images showing (a) moiré fringe patterns of the $U_{x}$ field after cutting from $\mathrm{AA}^{\prime}$, (b) the calculated displacement fields from the moiré fringe pattern and (c) strain distribution $\left(\varepsilon_{x}\right)$.

The method has proven itself adequate, accurate and economical if proper care is taken in the preparation of the specimen and the procedure of measurement. However, the sectioning method creates 
irreversible destruction to the specimen, hence is normally only used for certain specimens, such as thin plates.

\section{RING CORE METHOD}

The ring core method involves measuring the deformation in a central area caused by the cutting of an annular slot in the surrounding material, which was first proposed by Milbradt ${ }^{[7]}$ in 1951. Like the hole-drilling and crack compliance methods, the ring-core method can be used to evaluate the in-plane stresses, and additional incremental drillings as it can be used to evaluate the residual stresses in three dimensions.

The method was also combined with the optical method and applied to investigating the residual stress in extremely small/micro- regions. In 2009, Korsunsky et al. ${ }^{[78]}$ conducted a study on the residual stress evaluation by measuring the strain change at the sample surface via DIC analysis of SEM micrographs for a regular pattern of dots deposited on the sample surface prior to ring drilling. Sebastiani et al. ${ }^{[79]}$, in 2011, developed a modified FIB-DIC method to analyze the depth-resolved residual stress of thin coatings. In addition, Korsunsky et al. ${ }^{[80]}$, Kang et al. ${ }^{[81]}$ and Song et al. ${ }^{[82]}$ carried out similar studies when they evaluated the residual stress of thin coatings/films at the micrometer scale using FIB milling and DIC. Zhu ${ }^{[83]}$ fabricated an artificial lattice pattern on the interface of TBCs using FIB to serve as the deformation carrier in the latter measurement. They then created a circular band around the pattern by FIB milling, and DIC was implemented with scanning electron microscopy to obtain the in-plane strain. Figure 12 shows the SEM images for the patterned surface before

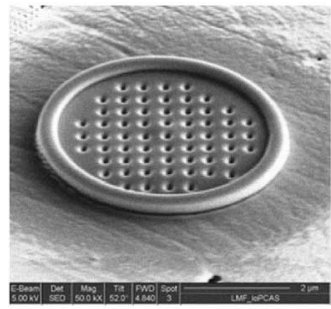

(a)

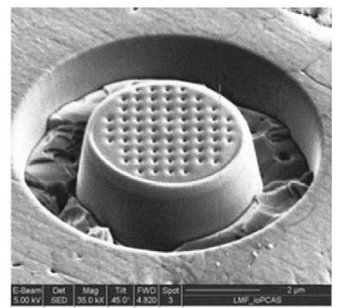

(b)

Fig. 12 SEM diagrams of the patterned surface (a) before milling and (b) after milling. and after milling.

The ring core method has an advantage over the hole-drilling method in that it provides much larger surface strains. However, the method is less frequently used because it creates much greater damage to the specimen and is much less convenient to implement in practice. Recently, the ring core method was applied to measuring the residual stress of a large steam turbine rotor, which was beneficial to high strain release rate and measuring accuracy.

\section{CRACK COMPLIANCE METHOD}

The crack compliance method ${ }^{[84]}$, also named the slotting method or the slitting method, involves cutting a small slot into the material to monitor the relaxation of stress in the vicinity of the crack. By incrementally increasing the depth of the slot, it is possible to resolve the stress field normal to the crack as a function of depth for relatively simple stress distributions. The slit can be introduced by a thin saw, milling cutter or wire used in electrical discharge machining (EDM).

In 2006, Sabaté et al. ${ }^{[85]}$ measured the local stress within a nano-scale thin film using the DIC crack compliance method. In 2009, Wang and Xie et al. ${ }^{[86]}$ assessed the residual stress of interconnections by slot milling with FIB and Geometric Phase Analysis (GPA), as shown in Fig.13.

The crack compliance method has the advantage over the hole-drilling method in that it can evaluate the stress profile over the entire specimen depth; the surface strain measurement providing data for the near-surface stresses and the back strain measurement providing data for the deeper stresses. However, the crack compliance method provides only the residual stress components normal to the cut surface, whereas the hole-drilling method provides all three in-plane stress components. Additional cuts need to be made to find other stress components, in which case the overall procedure resembles the sectioning method.

\section{LAYER REMOVAL METHOD}

The layer removal method ${ }^{[87,88]}$ is actually a Stoney method and involves observing the change of curvature caused by the (incremental) removal of a layer of material. The removal of the materials from the specimen surface can be implemented by chemical etching or mechanical milling. The initial 


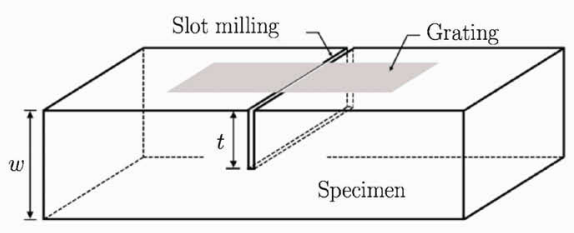

(a)

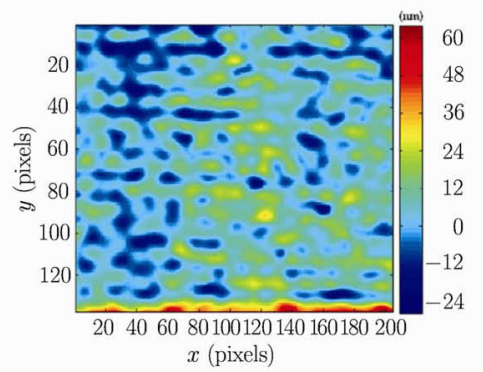

(c)

Step: Step-3

Increment 1: Step Time $=1.000$

Ly $\quad \begin{aligned} & \text { Increment 1: Step Ti } \\ & \text { Lrimary Var: } S, S 11\end{aligned}$

Deformed Var: U Deformation Scale Factor: $1.0 \times 10^{2}$

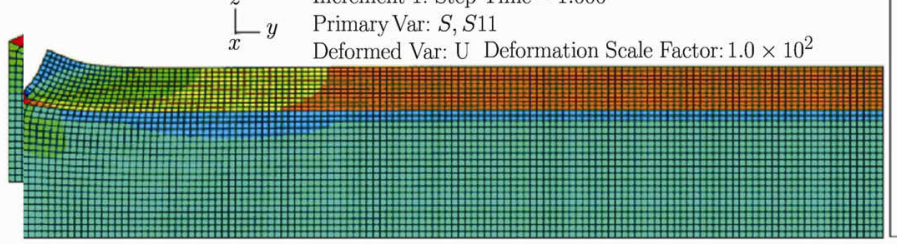

(e)

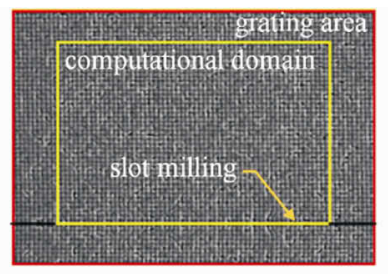

(b)

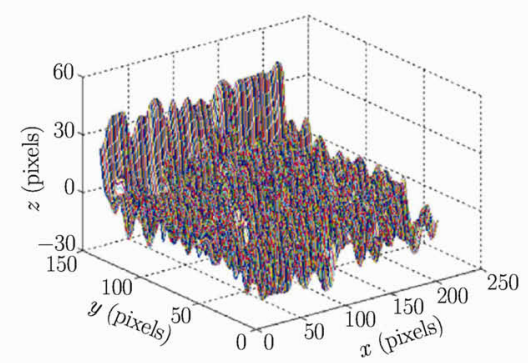

(d)

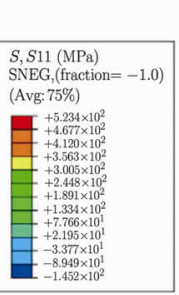

Fig. 13. (a) Schematic diagram of the crack compliance method combined with GPA; (b) the grating and the slot milling is fabricated using FIB; (c) residual displacement field in direction $y$ in the vicinity of the slot after slot milling calculated from GPA (2-D displacement field); (d) 3-D show of the displacement field; (e) the stress field of the sample after the constraint of the left edge of copper layer is removed by finite element method. (Reprinted with permission. Ref.[86] Copyright 2010, Elsevier)

distribution of the residual stress can be derived from curvature measurements, which can be conducted by advanced optical sensing with high sensitivity, such as Michelson interferometry, the fringe projection method $^{[89]}$ and $3 \mathrm{D}$ DIC ${ }^{[90]}$. Figure 14 shows the schematic diagram for residual stress measurement using the layer removal method combined with 3D DIC.

The method was first applied to measuring the residual stress of a round bar. Heyn ${ }^{[91]}$ milled the outer surface of the round bar layer by layer, and linked the relationship between the length change of the round bar and the radial residual stress. Hospers et al. ${ }^{[92]}$ studied the residual stresses of as-rolled sheet and spot-peened materials using the method. They removed the thin layers by chemical etching which induces an increased curvature of the sheet and then derived the initial distribution of the residual stress from curvature measurements.

The layer removal method is suited to flat plate and cylindrical specimens where the residual stresses are known to vary with depth, but needs to be uniformly parallel to the surface.

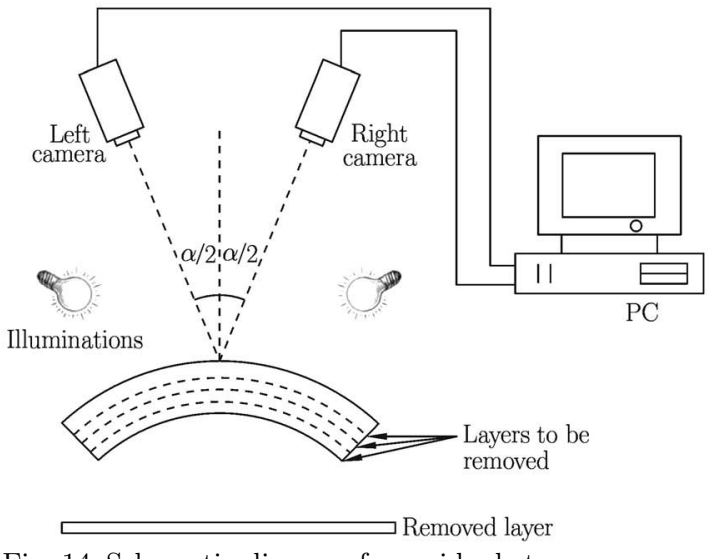

\section{DISCUSSION AND SUMMARY}

There is a wide variety of methods for measuring residual stress in different states and for different situations. When choosing an experimental scheme for practical measurement, the specific circumstances 
of the component, such as field feasibility and adaptability, expenses and efficiency, and so on, should be thoroughly considered. The mechanical release methods can be utilized to measure the elastic deformation directly induced by residual stress relaxation meaning that they can deliver highly accurate and reliable measurements, and can be applied to a wide range of working conditions. All of these make the mechanical release methods highly popular, although they may cause some damages to the measured object.

Compared with conventional strain gauge measurements for mechanically released stress, advanced optical sensing provides a simple, convenient and economical non-contact and high precision measurement and is adaptable to a wide range of machining geometries and sizes. Moreover, optical sensing can provide full field deformation information. And furthermore some additional data can be used to improve the accuracy of residual stress evaluation from mechanical release measurements.

Table 2 lists a comparison of the four most commonly used optical methods.

Table 2. Comparisons of the most commonly used optical methods

\begin{tabular}{ccc}
\hline Optical methods & $\begin{array}{c}\text { Optical sensing } \\
\text { element preparation }\end{array}$ & Comments \\
\hline Moiré interferometry & Grating & Flat surface \\
DIC & Speckles & Diffuse reflection surface; in-situ measurement \\
Laser speckle interferometry & - & In-situ measurement \\
Holography & - & Ditu measurement; convenient \\
\hline
\end{tabular}

At this time, techniques used for residual stress measurement have followed typical developmental trends. New ideas, advanced knowledge and innovative technology, such as optical sensing, advanced machining methods and fast computation capability, have continuously broadened application domains. An example is the application of FIB instrumentation to make microscopic cuts, holes, rings and slots in the sub-micron range. This development has dramatically extended the dimension scale of various residual stress measurement techniques into the micro- and nano-range.

In the future, developmental trends will be towards non-destructive, high precision and on-line measurements. Such methods offer benefits and convenience to the scientific research and industrial manufacture.

\section{References}

[1] Withers,P.J., Bhadeshia,H.K.D.H., Residual stress. Part 2-Nature and origins. Materials Science and Technology, 2001, 17(4): 366-375.

[2] Prevey,P., Residual stress in design. Process \& Material Selection, ASM, Metals Park, OH, 1987: 11-19.

[3] Grubisic,V. and Fischer,G., Procedure for reliable durability validation of train axles. Materialwissenschaft und Werkstofftechnik, 2006, 37(12): 973-982.

[4] Kim,K.S. and Hahn,H.T., Residual stress development during processing of graphite/epoxy composites. Composites Science and Technology, 1989, 36(2): 121-132.

[5] Torres,M.A.S. and Voorwald,H.J.C., An evaluation of shot peening, residual stress and stress relaxation on the fatigue life of AISI 4340 steel. International Journal of Fatigue, 2002, 24(8): 877-886.

[6] Sigl,L.S. and Evans,A.G., Effects of residual stress and frictional sliding on cracking and pull-out in brittle matrix composites. Mechanics of Materials, 1989, 8(1): 1-12.

[7] Soyama,H., Park,J.D. and Saka,M., Use of cavitating jet for introducing compressive residual stress. Journal of Manufacturing Science and Engineering, 2000, 122(1): 83-89.

[8] Jiang,W.C., Gong,J.M., Chen,H. and Tu,S.T., The effect of filler metal thickness on residual stress and creep for stainless-steel plate-fin structure. International Journal of Pressure Vessels and Piping, 2008, 85(8): 569-574.

[9] Withers,P.J. and Bhadeshia,H.K.D.H., Residual stress. Part 1-Measurement techniques. Materials Science and Technology, 2001, 17(4): 355-365.

[10] Schajer,G.S., Relaxation methods for measuring residual stresses, techniques and opportunities. Experimental Mechanics, 2010, 50(8): 1117-1127.

[11] Prevey,P.S., X-ray diffraction residual stress techniques. Metals Handbook 10, ASM, Metals Park, OH, 1986, 380-392.

[12] Jiles,D.C., Review of magnetic methods for nondestructive evaluation. NDT International, 1988, 21(5): 311-319. 
[13] Dike,J.J. and Johson,G.C., Residual stress determination using acoustoelasticity. NDT and E International, 1995, 28(2): 117-117(1).

[14] Allen,A.J., Hutchings,M.T., Windsor C.G., et al., Neutron diffraction methods for the study of residual stress fields. Advances in Physics, 1985, 34(4): 445-473.

[15] Ager,III.J.W. and Drory,M.D., Quantitative measurement of residual biaxial stress by Raman spectroscopy in diamond grown on a Ti alloy by chemical vapor deposition. Physical Review B, 1993, 48(4): 2601-2607.

[16] American Society for Testing Materials (ASTM) E837-01, Standard test method for determining residual stresses by the hole-drilling strain-gage method, 2001.

[17] American Society for Testing Materials (ASTM) E837-08, Standard test method for determining residual stresses by the hole-drilling strain-gage method, 2008.

[18] Nelson,D.V., Residual stress determination by hole drilling combined with optical methods. Experimental Mechanics, 2010, 50(2): 145-158.

[19] Shui,G.S. and Wang,Y.S., Characterization of surface damage of a solid plate under tensile loading using nonlinear Rayleigh waves. Theoretical and Applied Mechanics Letters, 2011, 1(5): 051005.

[20] Luo,Y., Wang,Z.P., Xu,B.Q. and Yuan,F., The pre-stack migration imaging technique for damages identification inconcrete structures. Theoretical and Applied Mechanics Letters, 2011, 1(5): 051004.

[21] Jiang,G., Tan,M.H., Wang,W.M. and He,W., Present research status of measuring residual stress. Machine Tool \& Hydraulics, 2007, 35(6): 213-220 (in Chinese).

[22] Mathar,J., Determination of initial stresses by measuring the deformations around drilled holes. Transactions of the American Society of Mechanical Engineers, 1934, 56(2): 249-254.

[23] Soete,W. and Vancrombrugge,R., An industrial method for the determination of residual stress. Proceedings of SESA, 1950, 8(1): 17-28.

[24] Rendler,N.J. and Vigness,I., Hole-drilling strain-gage method of measuring residual stresses. Experimental Mechanics, 1966, 6(12): 577-586.

[25] Post,D. and Baracat,W.A., High-sensitivity moiré interferometry-A simplified approach. Experimental Mechanics, 1981, 21(3): 100-104.

[26] McDonach,A., Mckelvie,J., MacKenzie,P., et al., Improved moiré interferometry and applications in fracture mechanics, residual stresses and damaged composites. Experimental Techniques, 1983, 7(6): 20-24.

[27] Nicoletto,G., Theoretical fringe analysis for a coherent optics method of residual stress measurement. Journal of Strain Analysis for Engineering Design, 1988, 23(4): 169-178.

[28] Ya,M., Miao,H., Zhang,X. and Lu,J., Determination of residual stress by use of phase shifting moiré interferometry and hole-drilling method. Optics and Lasers in Engineering, 2006, 44(1): 68-79.

[29] Ya,M., Xing,Y.M., Dai,F.L., Lu,K. and Lu,J., Study of residual stress in surface nanostructured AISI 316L stainless steel using two mechanical methods. Surface and Coatings Technology, 2003, 168(2-3): 148-155.

[30] Wang,Q., Wang,B., Ma,D.C. and Dai,F.L., Residual stress measurement for Ion-implanted NiTi alloy by using moiré interferometry and hole-drilling combined method. Chinese Journal of Aeronautics, 2006, 19: S23-S26.

[31] Ya,M., Experimental Study and Application of Moiré Interferometry Hole Drilling Method for Residual Stress Measurement. Doctoral dissertation, Tsinghua University, 2002 (in Chinese).

[32] Zou,D.Q., High Temperature Moiré Interferometry Technique and Its Applications. Doctoral dissertation, Tsinghua University, 1996 (in Chinese).

[33] Ya,M., Dai,F.L., Xie,H.M. and Lü,J., Measurement of non-uniform residual stresses by combined moiré interferometry and hole-drilling method, theory, experimental method and applications. Acta Mechanica Sinica, 2003, 19(6): 567-574.

[34] Shankar,K., Xie,H.M., Wei,R.Y., Asundi,A. and Boay,C.G., A study on residual stresses in polymer composites using moiré interferometry. Advanced Composite Materials, 2004, 13(3-4): 237-253.

[35] Xie,H.M., Wang,Y.F., Tang,M.J., Liu,Z.W., Hu,Z.X., Lu,J. and Chen,P.W., Application of moiré interferometry to study residual deformation in lap-welded steel plates. Strain, 2011, 47(Suppl. 2): 311-319.

[36] Chang,H., Yao,H.S. and Hou,L.L., Combined phase shift moiré interference method with blind hole method to expect composite materials residual stress. Chinese Quarterly of Mechanics, 2006, 27: 511-514 (in Chinese).

[37] Chen,J.B. and Yu,Z.Y., Measurement of residual stresses on grinding surface by three directional grating and moiré interference. Chinese Journal of Mechanical Engineering, 2000, 36: 102-105 (in Chinese).

[38] Chen,J.B., Zhou,B.M. and Ginesu,F., Measurement on residual stress by grating rosette and moiré interferometry. Chinese Journal of Lasers, 2001, A28: 746-748 (in Chinese).

[39] Liu,Z.W., Zhou,J.F., Huang,X.F., Lu,J. and Xie,H.M., Residual strain evaluation of curved surface by grating-transferring technique and GPA. Theoretical and Applied Mechanics Letters, 2011, 1(5): 051007 
[40] Zhou,J.F., Liu,Z.W., Xie,H.M. and Li,K.Y., Phase-shifting moiré interferometry for residual strain measurement. In: Distribution Analysis of Displacements and Strains, Proceedings of SPIE 7375, ICEM 2008: International Conference on Experimental Mechanics, 2008, 737546.

[41] Liu,Z.W., Zhou,J.F., Wu,C.L. and Xie,H.M., GPA combined with the hole-drilling method applied for curved surface strain measurement. Strain, 2013, 49(1): 46-53.

[42] Xie,H.M., Preface for special subject, recent development of experimental mechanics methods and their applications in engineering. Theoretical and applied mechanics letters, 2011, 1(5): 051000.

[43] Sutton,M.A., McNeill,S.R., Helm,J.D. and Chao,Y.J., Advances in two-dimensional and three-dimensional computer vision. In: Rastogi PK (ed) Chapter 10 in 'Photomechanics'. Springer, Heidelberg, 2000.

[44] Ma,Y.J., Xiong,T.C. and Yao,X.F., Experimental investigation of interface curing stresses between PMMA and composite using digital speckle correlation method. Theoretical and Applied Mechanics Letters, 2011, 1(5): 051003.

[45] Zhou,Z.B., Chen,P.W., Guo,B.Q., Duan,Z.P. and Huang,F.L., Quasi-static tensile deformation and fracture behavior of a highly particle-filled composite using digital image correlation method. Theoretical and Applied Mechanics Letters, 2011, 1(5): 051002.

[46] Nelson,D.V., Makino,A. and Schmidt,T., Residual stress determination using hole drilling and 3D image correlation. Experimental Mechanics, 2006, 46(1): 31-38.

[47] Lord,J.D., Penn,D. and Whitehead,P., The application of digital image correlation for measuring residual stress by incremental hole drilling. Applied Mechanics and Materials, 2008, 13-14: 65-73

[48] Gao,J.X. and Shang,H.X., Deformation-pattern-based digital image correlation method and its application to residual stress measurement. Applied Optics, 2009, 48(7): 1371-1381.

[49] Xie,H.M., et al., A method and system for measuring residual stress in real time, Chinese Patent, 2011 (in Chinese).

[50] Yao,X.F., et al., A residual stress measurement method and system for a curved tube, Chinese Patent, 2011 (in Chinese).

[51] Sabaté,N., Vogel,D., Gollhardt,A., Keller,J., Cane,C., Gracia,I., Morante,J.R. and Michel,B., Residual stress measurement on a MEMS structure with high-spatial resolution. Journal of Microelectromechanical Systems, 2007, 16(2): 365-372

[52] Wykes,C., Use of electronic speckle pattern interferometry (ESPI) in the measurement of static and dynamic surface displacements. Optical Engineering, 1982, 21(3): 213400.

[53] Hung,Y.Y. and Ho,H.P., Shearography, an optical measurement technique and applications. Materials Science and Engineering: R: Reports, 2005, 49(3): 61-87.

[54] Zhang,J., Two-dimensional in-plane electronic speckle pattern interferometer and its application to residual stress determination. Optical Engineering, 1998, 37: 2402-2409.

[55] Zhang,J. and Chong,T.C., Fiber electronic speckle pattern interferometry and its applications in residual stress measurements. Applied Optics, 1998, 37(8): 6707-6714.

[56] Schmitt,D.R. and Hunt,R.W., Inversion of speckle interferometer fringes for hole-drilling residual stress determinations. Experimental Mechanics, 2000, 40(2): 129-137.

[57] Steinzig,M. and Ponslet,E., Residual stress measurement using the hole drilling method and laser speckle interferometry, Part I. Experimental Techniques, 2003, 27(3): 43-46.

[58] Ponslet,E. and Steinzig,M., Residual stress measurement using the hole drilling method and laser speckle interferometry, Part II, analysis technique. Experimental Techniques, 2003, 27(4): 17-21.

[59] Ponslet,E. and Steinzig,M., Residual stress measurement using the hole drilling method and laser speckle interferometry, Part III, analysis technique. Experimental Techniques, 2003, 27(5): 45-48.

[60] Steinzig,M. and Takahashi,T., Residual stress measurement using the hole drilling method and laser speckle interferometry, Part IV, measurement accuracy. Experimental Techniques, 2003, 27(6): 59-63.

[61] Xiao,Z., Fok,W.C. and Lwin,D.T., Parametric study of residual stress due to shot peening. Journal of Materials Processing Technology, 1993, 39(3-4): 469-483.

[62] Díaz,F.V., Kaufmann,G.H. and Galizzi,G.E., Determination of residual stresses using hole drilling and digital speckle pattern interferometry with automated data analysis. Optics and Lasers in Engineering, 2000, 33(1): 39-48.

[63] Hung,Y.Y., Long,K.W. and Wang,J.Q., Measurement of residual stress by phase shift shearography. Optics and Lasers in Engineering, 1997, 27(1): 61-73.

[64] Vest,C., Holographic Interferometry. New York: Wiley, John Wiley and Sons, Inc., 1979.

[65] Yang,C. and Miao,H., Vibration parameter measurement using the temporal digital hologram sequence and windowed Fourier transform. Theoretical and applied mechanics letters, 2011, 1(5): 051008.

[66] Schedin,S., Digital holographic interferometry. Journal of Holography and Speckle, 2006, 3(1): 1-17.

[67] Steffens,H.D. and Crostack,H.A., Measurement of residual stress in spot welded joints. In: International Conference of Residual Stresses in Welded Construction and Their Effects. London, The Welding Institute, 1978: 295-305. 
[68] Antonov,A.A., Morozov,V.K. and Chernyshev,G.N., Stress measurement by the method of disturbedsurface holography. Mechanics of Solids, 1988, 23: 179-184.

[69] Lobanov,L.M., et al., Determination of residual stresses by holographic interferometry using on hologram. Soviet Physics-Doklady, 1983, 28: 565-566.

[70] Rassokha,A.A. and Talalaev,N.N., Evaluation of residual stresses in welded joint of thin plate by a holographic method. Industrial Laboratory, 1983, 48(11): 1143-1146

[71] Nelson,D.V. and McCrickerd,J.T., Residual-stress determination through combined use of holographic interferometry and blind-hole drilling. Experimental Mechanics, 1986, 26(4): 371-378.

[72] Makino,A. and Nelson,D., Residual-stress determination by single-axis holographic interferometry and hole drilling - Part I, Theory. Experimental Mechanics, 1994, 34(1): 66-78.

[73] Steinzig,M., Hayman,G. and Rangaswamy,P., Data reduction methods for digital holographic residual stress measurement. In: Proceedings of SEM Annual Conference and Exposition on Experimental and Applied Mechanics, June 4-6, Portland, OR, 2001.

[74] Tebedge,N., Alpsten,G. and Tall,L., Residual-stress measurement by the sectioning method. Experimental Mechanics, 1973, 13(2): 88-96.

[75] Liu,Z.W., Wu,N.N., Huang,X.F., Xie,H.M., et al., Study of anti-laser irradiation performance of shot-peened 40CrNiMoA alloy steel. Materials Science \& Engineering A, 2012, 558: 675-683.

[76] Zhu,J.G., Xie,H.M., Hu,Z.M., Chen,P.W. and Zhang,Q.M., Cross-sectional residual stresses in thermal spray coatings measured by moiré interferometry and nanoindentation technique. Journal of Thermal Spray Technology, 2012, 21(5): 810-817.

[77] Milbradt,K.P., Ring-method determination of residual stresses. Proc SESA, 1951, 9(1): 63-74.

[78] Korsunsky,A., Sebastiani M. and Bemporad E., Focused ion beam ring drilling for residual stress evaluation. Materials Letters, 2009, 63(22): 1961-1963.

[79] Sebastiani,M., Eberl,C., Bemporad,E. and Pharr,G.M., Depth-resolved residual stress analysis of thin coatings by a new FIB-DIC method. Materials Science \& Engineering A, 2011, 528(27): 7901-7908.

[80] Korsunsky,A.M., Sebastiani,M. and Bemporadb,E., Residual stress evaluation at the micrometer scale, Analysis of thin coatings by FIB milling and digital image correlation. Surface and Coatings Technology, 2010, 205(7): 2393-2403.

[81] Kang,K.J., Yao,N., He,M.Y. and Evans,A.G., A method for in situ measurement of the residual stress in thin films byusing the focused ion beam. Thin Solid Films, 2003, 443(1-2): 71-77.

[82] Song,X., Yeap,K.B., Zhu,J., Belnoue,J., Sebastiani,M., Bemporad,E., Zeng,K.Y. and Korsunsky,A.M., Residual stress measurement in thin films at sub-micron scale using Focused Ion Beam milling and imaging. Thin Solid Films, 2012, 520(6): 2073-2076.

[83] Zhu,J.G., Experimental Measurement and Numerical Analysis of Residual Stress on Thermal Barrier Coatings. Doctoral dissertation, Tsinghua University, Beijing, 2013 (in Chinese).

[84] Nowell,D., Tochilin,S. and Hills,D.A., Measurement of residual stress in beams and plates using the crack compliance technique. Journal of Strain Analysis, 2000, 35(4): 277-285.

[85] Sabaté,N., Vogel,D., Gollhardt,A., Marcos,J., Gràcia,I., Cané,C. and Michel,B., Digital image correlation of nanoscale deformation fields for local stress measurement in thin films. Nanotechnology, 2006, 17(20): 5264-5270.

[86] Wang,Q.H., Xie,H.M., Liu,Z.W., Lou,X.H., Wang,J.F., Xu,K.W., Zhang,Z.H., Liao,J.H. and Gu,C.Z., Residual stress assessment of interconnects by slot milling with FIB and geometric phase analysis. $O p$ tics and Lasers in Engineering, 2010, 48(11): 1113-1118.

[87] Lima,C.R.C., Nin,J. and Guilemany,J.M., Evaluation of residual stresses of thermal barrier coatings with HVOF thermally sprayed bond coats using the Modified Layer Removal Method (MLRM). Surface 86 Coatings Technology, 2006, 200(20-21): 5963-5972.

[88] Greving,D.J., Rybicki,E.F. and Shadley,J.R., Through-thickness residual stress evaluations for several industrial thermal spray coatings using a modified layer-removal method. Journal of Thermal Spray Technology, 1994, 3(4): 379-388.

[89] Anna,T., Dubey,S.K., Shakher,C., Roy,A. and Mehta,D.S., Sinusoidal fringe projection system based on compact and non-mechanical scanning low-coherence Michelson interferometer for three-dimensional shape measurement. Optics Communications, 2009, 282(7): 1237-1242.

[90] Zhu,J.G., Xie,H.M., Hu,Z.X., Chen,P.W. and Zhang,Q.M., Residual stress in thermal spray coatings measured by curvature based on 3D digital image correlation technique. Surface \& Coatings Technology, 2011, 206(6): 1396-1402.

[91] Heyn,E., Internal strains in cold-wrought metals, and some troubles caused thereby. Journal of the Institute of Metals, 1914, 12: 3-37.

[92] Hospers,F. and Vogelesang,L.B., Determination of residual stresses in aluminum-alloy sheet material. Experimental Mechanics, 1975, 15(3): 107-110. 